\title{
A Supremacia Judicial em sua Essência: para além do casuísmo teórico ${ }^{1}$
}

\author{
The Judicial Supremacy on its Core: to beyond theoretical casuism
}

\author{
Carlos Bolonha \\ Fabrício Faroni \\ Henrique Rangel
}

\begin{abstract}
Resumo: Este artigo busca uma compreensão filosófica, no plano da ontognosiologia, acerca da supremacia judicial, discutindo o que seria este fenômeno jurídico-político em sua essência. Acredita-se que essa compreensão abstrata da supremacia judicial possa ser obtida por uma análise hipotética de situações correspondentes a fatores de potencial aproximação ou afastamento de uma preponderância da atividade judiciária perante os poderes eleitos. Considera-se a existência de, pelo menos, quatro fatores: (1) o bom funcionamento dos poderes eleitos; (2) o bom funcionamento da atividade judiciária; (3) o comprometimento com os direitos; e (4) o desacordo moral sobre o conteúdo dos direitos.
\end{abstract}

Palavras-chave: Judicial Review. Supremacia Judicial. Desenhos Institucionais.

\begin{abstract}
The present study develops a philosophical conception of judicial supremacy, in the ontognosiology level. Observing this legal-political phenomenon in its core, we defend that the abstract conception of judicial supremacy can be obtained by an exam of hypothetical situations corresponding to potential approach or potential removal factors of a judicial superiority before elected branches. In this sense, it is possible to consider at least four factors: (1) the well-functioning of the elected branches; (2) the wellfunctioning of the judicial activity; (3) the commitment with rights; and (4) the moral disagreement on the content of rights.
\end{abstract}

Keywords: Judicial Review. Judicial Supremacy. Institutional Design.

Este artigo foi elaborado no âmbito do Laboratório de Estudos Teóricos e Analíticos sobre o Comportamento das Instituições (LETACI), vinculado à Faculdade Nacional de Direito e ao Programa de Pós-Graduação em Direito da Universidade Federal do Rio de Janeiro e com financiamento da Fundação Carlos Chagas Filho de Amparo à Pesquisa do Estado do Rio de Janeiro (FAPERJ), além do Conselho Nacional de Desenvolvimento Científico e Tecnológico (CNPq).

Recebido em: 21/07/2012.

Revisado em: 07/10/2012.

Aprovado em: 08/11/2012. 


\section{Introdução}

No debate sobre o judicial review, iniciado na segunda metade do século XX, destacadamente nos Estados Unidos da América (EUA) e no Canadá, e mais recentemente no Brasil, muito se tem discutido sobre supremacia judicial. Inúmeros trabalhos têm se dedicado especialmente ao tema, identificando, por exemplo, como a atividade judicial ganhou, no âmbito deste arranjo institucional, contornos políticos (ELY, 1980; WHITTINGTON, 2007), e, da mesma forma, como o judicial review serviu de instrumento para uma Suprema Corte adotar um comportamento ativista $^{2}$. A maioria se desenvolve tendo como proposta a defesa ou a oposição do seu exercício, sendo a legitimidade uma questão normalmente mantida, ao menos, como pano de fundo ${ }^{3}$. Um número menor, porém,

2 Para compreender como um método de análise do judicial review baseado em dois critérios - scope e enforcement - pode apresentar distintos casos de ativismo judicial. (GRIFFIN, 1999)

3 Existe uma trajetória de apoio e oposição ao judicial review na história constitucional norte-americana, tendo como base a tradicional classificação entre liberais e conservadores. O judicial review, embora tenha sido criado em 1803, na decisão de Marbury v. Madison, somente passou a ser usado regularmente, como um poder consolidado na Corte, em um período conhecido como a Era Lochner. Nessa era, o apoio vinha de conservadores, pois as decisões da Suprema Corte possuíam um perfil de proteção da propriedade ainda muito destacado, não se dispondo desse poder para intervenções políticas mais profundas. Esse arranjo institucional, na concepção de Vermeule como desenho de larga escala, passou a ser defendido pelos liberais a partir de 1937, quando a Suprema Corte se "adequou" ao plano de governo intervencionista do Presidente Franklin Delano Roosevelt, sobretudo após a tentativa de exercer a competência do court-packing. Com uma Suprema Corte mais de vanguarda, colaborando com um plano liberal de governo, o judicial review passou a sofrer oposições por parte dos conservadores. Somente a partir de uma era mais conservadora da Suprema Corte, com a liderança do Chief Justice William Rehnquist, o judicial review reconquistou a defesa dos conservadores. São exemplos dessa era conservadora da Corte a invalidação da Violence Against Women Act, no caso United States v. Morrison, e a invalidação de lei que proíbe posse de arma na proximidade de escolas, no caso United States v. Lopez. Atualmente, na chefia de John Robert Jr., após espasmos de progressivismos, liberais passam a reconsiderar a oposição ao judicial review que vinham mantendo e começam a defender formas brandas de seu exercício. A análise que se costuma traçar, porém, deve reconhecer a importância de um estudo que considere o perfil da maioria da Suprema Corte e o perfil predominante nos poderes eleitos. Cf. os casos Marbury v. Madison, 5 U.S. 137 (1803); United States v. Morrison, 
contribuiu mais intensamente ao debate quando, com maior rigor científico e imparcialidade, buscou analisar o tema elaborando critérios que definissem razoavelmente a supremacia judicial. Ainda assim, em meio a tais contribuições, é possível afirmar que persiste certa dificuldade na compreensão da supremacia judicial.

Epistemologicamente, o fenômeno da supremacia judicial parece não possuir um significado bem delimitado. Ainda um objeto de recentes estudos, não atingiu uma condição rigorosa de categoria conceitual. Ciente da necessidade de se distinguirem os momentos em que esse fenômeno é estudado no plano teórico e abstrato dos momentos em que seu estudo é mais exemplificativo e contextualizado, o objetivo deste artigo é tentar contribuir para a consolidação de uma compreensão ontognosiológica da supremacia judicial. Em outras palavras, trata-se de um estudo sensível ao que seria a essência da supremacia judicial, afastando-se as possibilidades de sua expressão ${ }^{4}$.

\section{O Berço do Debate: a relação entre os poderes e o judicial re- view}

As críticas ao judicial review apresentam como tese principal a ideia de intervenção em matérias políticas pertinentes à atividade de governo. Exemplo disso é o frequente questionamento de sua legitimidade tendo como argumento central a condição de os poderes eleitos serem aqueles que melhor desempenham essa função ${ }^{5}$. Os EUA, desde a Constituição de

529 U.S. 598 (2000); e United States v. Lopez, 514 U.S. 549 (1995). Sobre a visão de desenhos institucionais em larga e pequena escala, ver Vermeule (2007).

4 Dessa maneira, as referências seguintes à supremacia judicial, feita a delimitação acima do objeto, ocorrerão por meio do termo supremacia judicial abstrata, compreendida como uma forma de estudo sobre sua essência. As formas de expressão da supremacia judicial ficam a cargo da supremacia judicial especifica.

5 Jeremy Waldron, por exemplo, não acredita que tenha ele apresentado claramente qual seria a objeção ao judicial review, nem mesmo ter respondido adequadamente às críticas formuladas ao seu livro Law and Desagreement. Por isso, buscou elaborar um argumento essencial de oposição ao judicial review. Este se constitui sobre razões relacionadas ao processo e razões relacionadas ao resultado. (WALDRON, 2010, p. 98) 
1787, buscaram desenvolver um desenho institucional baseado na simetria entre os branches ${ }^{6}$. Com o legado teórico de Montesquieu, importou-se a máxima da separação de poderes, e os EUA cuidaram de estabelecer o seu próprio modelo de repartição de competências e mecanismos de checks and balances. Desde o início, seguindo os pensamentos dos Founding Fathers, havia a preocupação de dividir os poderes, configurando-se, como parâmetro organizacional, o equilíbrio destes. Esse equilíbrio foi reforçado em 1803, quando a Corte de Marshall (1801-1835) instituiu o judicial review, à época, compreendido como uma doutrina. O desenho simétrico, entretanto, sofreu grande alteração posteriormente, na segunda metade do século XX. Nesse momento, o judicial review obteve especial destaque e seu uso mais frequente e intenso, nas Cortes de Warren e de Burger (1953-1969/1969-1986), resultou em um período comumente reportado como de supremacia judicial ${ }^{7}$.

Em um primeiro momento do judicial review, à época de sua instituição, somente havia a pretensão de reforçar a simetria entre poderes de Estado. Há quem defenda, no entanto, que a doutrina do judicial review foi criada com a precípua finalidade de garantir a independência judicial que estava sendo ultrajada àquele momento (NELSON, 2000). A Suprema Corte vinha sofrendo influências partidárias sobre sua atuação e servindo de móbil para o sucesso de um programa federalista. Com isso, os Justices eram nomeados e pressionados pelo governo com o fim de garantir a manutenção de sua plataforma partidária. Por essas razões, a Corte de Marshall iniciou uma atividade que pudesse afastar a Suprema Corte de tais influências.

A decisão em Marbury v. Madison definiu que a Suprema Corte somente possuiria legitimidade para invalidar atos do Legislativo e do Executivo que atentassem contra questões imutáveis, sendo o maior exemplo

\footnotetext{
6 Ressalte-se que há uma terminologia comum, nos EUA, com o vocábulo branches "departamentos" - para aquilo que compreendemos, no Brasil, como poderes de Estado, enquanto powers representam as competências constitucionais específicas.

7 Exemplo disso é a denominação cunhada por Stephen Griffin para esse período. Apesar de a decisão do caso Marbury ter criado a doutrina do judicial review, foi na metade do século XX que ganhou maior expressão. (GRIFFIN, 2005)
} 
para isso a propriedade ${ }^{8}$. Havendo controvérsia correspondente a fundamental law, a Corte estaria apta a agir; do contrário, sendo matéria típica de flutuação político-partidária, a Corte deveria se afastar. Esse comportamento consolidou-se, posteriormente, como a political question doctrine, isto é, somente aplicar o instituto do judicial review na incidência de uma legal discretion ${ }^{9}$. Essa doutrina reforça o judicial review a restaurar a independência do judiciário quando o habilita a atuar somente em questões de discricionariedade legal, não podendo intervir em questões de ordem governamental. Somente em um segundo momento, na segunda metade do século XX, assuntos correlatos a uma political discretion passaram a observar o avanço da Suprema Corte, notadamente com o advento das Cortes de Warren e de Burger. O judicial review passou a ser um relevante instrumento de deliberação política e de atendimento a demandas da sociedade. Grande parte dos parâmetros de deliberação nos assuntos mais controvertidos da sociedade remonta a essa época ${ }^{10}$.

Por isso, é possível afirmar que o judicial review teve seu espectro de aplicabilidade significativamente ampliado. A história constitucional

8 Os chamados taking cases, exemplos de legislação estadual que violavam a propriedade privada, de acordo com o trecho a seguir foram: "[...] cases in which legislators sought either to take alleged property rights from original owners and grant them to others or to limit the original owners' use rights" (NELSON, 2000, p. 79). São exemplos de taking cases os casos: Flecher v. Peck, 10 U.S. 87 (1810)- lei do Estado da Georgia; e Trustees of Dartmouth College v. Woodward, 17 U.S. 518 (1819) - lei do Estado de New Hampshire. Ressalte-se que os taking cases, sempre sobre legislação estadual nesse período, foram os únicos casos de exercício dessa doutrina entre o caso Marbury, de 1803, e o caso Dread Scott, de 1857; portanto, somente após 54 anos uma lei federal foi objeto de invalidação pelo judicial review pela segunda vez. Cf. os casos Marbury v. Madison, 5 U.S. 137 (1803), e Scott v. Sandford, 60 U.S. 393 (1857).

9 United States v. The William, 28 Fed. Cas. 614, no. 16,700 D.Mass. (1808).

${ }^{10}$ É possível elencar alguns dos grandes casos de repercussão e marcante atuação política da Suprema Corte durante esse período. Pode-se mencionar para a Corte de Warren: Brown v. Board of Education, 347 U.S. 483 (1954); New York Times Co. v. Sullivan, 376 U.S. 254 (1964); Griswold v. Connecticut, 381 U.S. 479 (1965); Miranda v. Arizona, 384 U.S. 436 (1966); Red Lion Broadcasting Co. v. FCC, 395 U.S. 367 (1969). Para a Corte de Burger: Roe v. Wade, 410 U.S. 113 (1973); Swann v. Charlotte-Mecklenburg Board of Education, 402 U.S. 1 (1971); United States v. Nixon, 418 U.S. 683 (1974); Regents of the University of California v. Bakke, 438 U.S. 265 (1978). 
norte-americana observou a influência do judicial review no estabelecimento e nas alterações das conjunturas da dinâmica entre os poderes. $\mathrm{O}$ judicial review tanto pode reforçar parâmetros de organização do Estado, no sentido de consagrar uma simetria entre poderes, como, até mesmo, ser protagonista da recondução de sua postura na direção de uma supremacia judicial.

\section{Pressuposto Metodológico para a Compreensão da Suprema- cia Judicial}

A presente análise sobre supremacia judicial considera a possibilidade de, pelo menos, duas perspectivas distintas de compreensão do fenômeno: (I) a supremacia judicial como uma concepção no plano abstrato de desenho institucional (supremacia judicial abstrata); e (II) a supremacia judicial como uma concepção de modelo concreto de desenho institucional (supremacia judicial específica) ${ }^{11}$.

11 Na defesa dessa categoria, qual seja, a supremacia judicial específica, é necessário observar outro aspecto terminológico. Em recente trabalho, Rodrigo Brandão, ao se dedicar à mesma temática do presente artigo, estabeleceu, para sua análise, uma categoria metodológica chamada "supremacia judicial em sentido estrito" (ou stricto sensu). Ressalta-se, aqui, não se tratar da mesma categoria já estabelecida (supremacia judicial especifica). A categoria de Brandão representa um ponto que lhe parece de essencial importância para abordar o debate "supremacia judicial vs. diálogos institucionais". Nesse âmbito, costuma-se dar fundamental importância para quem tem o poder de conferir a última palavra sobre uma determinada controvérsia na ordem constitucional democrática. Os autores deste debate geralmente - e assim como Brandão - costumam afirmar que a supremacia judicial existe quando o judiciário detém essa prerrogativa, deixando todos os demais entendimentos e exemplos como sensíveis à ala dialógica. Em suas palavras: “A supremacia judicial é, portanto, um minus em relação ao monopólio judicial, pois, como a última afirma que a atividade de interpretar a Constituição deve ser desempenhada, exclusivamente, pelo Judiciário, a primeira admite que os outros Poderes interpretem a Constituição, ressalvando, porém, que a exegese judicial é a final. Em outras palavras: o monopólio judicial confere ao Judiciário a única palavra em matéria de interpretação constitucional (uma espécie de 'reserva judicial'), enquanto a 'supremacia judicial' admite que o legislador tenha a primeira palavra, conferindo, porém, ao Judiciário a última. [...] A bem da verdade, a tese segundo a qual a exegese do Judiciário constitui um 'precedente vinculante' para a subsequente interpretação constitucional perpetrada pelos 'poderes' (especialmente pelo Parlamento) e pela sociedade civil é, precisamente, a supremacia 
Ambas as perspectivas, aqui defendidas, preocupam-se em compreender o fenômeno da supremacia judicial sob a ótica da atividade do judiciário frente aos outros poderes. É de se observar, contudo, que as duas perspectivas se distanciam pelo plano de concepção. A abstrata se encontra em uma concepção filosófica sobre um ideal realizável. A específica se encontra em uma concepção concreta da própria atividade institucional resultante da dinâmica sociopolítico-jurídica.

Sob a perspectiva abstrata, compreende-se que existe a proeminência da atividade do judiciário em detrimento dos demais poderes eleitos. Especifica-se isoladamente a concepção de supremacia judicial além dos efeitos de situações concretas e práticas da atividade institucional. Em contrapartida, acredita-se que, no plano concreto, a supremacia judicial revela-se não mais como um ideal a ser desenhado, mas como resultado específico da atividade judiciária de determinado Estado frente aos outros poderes. Nessa perspectiva de supremacia judicial, é possível conceber um modelo historicamente contextualizado e real de desenho institucional, que, por sua vez, fornece exemplos característicos de o que seria predomínio da atividade judicial.

Partindo desse pressuposto metodológico - uma concepção abstrata e uma concepção concreta de supremacia judicial - é possível obter-se uma perspectiva filosófica ontognosiológica, isto é, um objeto analisado em sua própria essência, e outra perspectiva sensível às ciências jurídica e política, analisando suas formas de expressão.

Do ponto de vista metodológico, há de se enfrentar, por um lado, o que é essencialmente a supremacia judicial, isto é, um fenômeno específico da ordem constitucional. Por outro, as diferentes formas de expressões concretas desse fenômeno que alteram a realidade constitucional. Assim,

judicial (em sentido estrito). Segundo tal concepção, em todas as questões constitucionais que possam ser submetidas aos Tribunais, o sentido que os juízos atribuíram à Constituição deve ser compreendido como definitivo para o futuro, seja no âmbito do próprio Judiciário, seja no âmbito dos demais 'poderes' e da sociedade" (BRANDÃO, 2012, p. 15). Talvez uma análise das formas de expressão da supremacia judicial, o que aqui ficou consignado como supremacia judicial específica, possa demonstrar que esta prerrogativa da palavra final seja um relevante indicativo deste desenho, mas longe de ser o único ou central parâmetro para analisar um fenômeno tão complexo como a supremacia judicial. 
exemplificando tais formas de expressão, supremacia judicial pode ser, por exemplo, um modelo em que a Suprema Corte detenha a prerrogativa de estabilizar o debate sobre aborto adotando determinado posicionamento moral antes que este desacordo moral tenha sido superado na respectiva sociedade. Supremacia judicial pode ser, ainda, um modelo em que a Corte Constitucional assegura possuir a última palavra inquestionável, e isso é aceito pelos outros poderes eleitos, pela mídia, pela opinião pública e pelo povo em geral.

Apresentado o pressuposto metodológico para o estudo da supremacia judicial, a perspectiva que se adota presentemente é a abstrata, no campo filosófico-ontognosiológico.

\section{Uma Compreensão de Supremacia Judicial Abstrata}

Partindo-se do pressuposto metodológico apresentado, fica mais claro perceber em que aspectos as contribuições do debate sobre judicial review se aproveitam para um estudo particular da supremacia judicial abstrata. As referências centrais são os estudos que, mesmo com o objetivo de formular argumentos de oposição ao exercício do judicial review, abordam esse arranjo institucional em sua essência ${ }^{12}$.

12 Neste momento, a referência é direta ao seguinte trecho: "O que desejo fazer é encontrar um argumento essencial contra o judicial review que seja independente tanto de suas manifestações históricas quanto a questões acerca de seus efeitos específicos - as decisões (boas ou más) que ela produziu, os desgostos e as afirmações que nos legou. Quero enfocar os aspectos da oposição ao judicial review que se destacam dos argumentos quanto ao modo como os juízes exercem seus poderes e o espírito (deferencial ou ativista) no qual eles abordam a legislação levada a juízo para sua aprovação" (WALDRON, 2010, p. 96). Em primeiro lugar, Waldron parece buscar isentar-se de contextos políticos específicos em que o judicial review é exercido, ou seja, ele não quer ser um opositor para esse momento conservador da Suprema Corte e de domínio de determinado partido no governo, mas para o exercício do judicial review condicionado unicamente a seus pressupostos metodológicos. Waldron parece pretender discutir sobre o desacordo moral em uma perspectiva abstrata, quase revestido de um véu da ignorância, como se não conhecesse qual é a ideologia partidária predominante e o que vem sendo feito atualmente em termos de prática política. Pretende, unicamente, demonstrar como uma decisão sobre o conteúdo dos direitos tendenciosa a um posicionamento moral qualquer, sem entrar 
Em primeiro lugar, alguns autores desse debate costumam admitir uma especificação do objeto judicial review a partir de um critério de ordem material, o que será aproveitado na presente análise ${ }^{13}$. Somente aquele judicial review exercido em matéria de direitos será admitido, ou seja, o que se costuma chamar de strong judicial review ${ }^{14}$. Esse critério não será considerado aqui por um viés de grande exclusão, e sim de caráter negativo. Não se pretende abordar controvérsias relativas a temas como federalismo, conflito de competências, prerrogativas de função pública e regras de procedimento previstas na Constituição. Somente se admitem controvérsias relevantes à discussão sobre o conteúdo dos direitos. Em outras palavras, há um “[...] dissenso substancial em relação a quais direitos existem e em relação àquilo a que equivalem" (WALDRON, 2010, p. 113). O caráter do escrutínio não é afastar hipóteses em que haja margens de dúvida; ao contrário, havendo dúvida, possivelmente haverá dissenso sobre sua existência ou sobre o que equivalem. Portanto, tais hipóteses já representam exemplos de debate sobre o conteúdo dos direitos; ou seja, inclusive nos casos de dúvida sobre a existência de matéria de conteúdo dos direitos, trata-se de strong judicial review. Por exemplo, um caso de separação de poderes que enseje a discussão sobre um direito individual pode ser tratado como um caso de strong judicial review.

no mérito de sua correção, seria ilegítima se o desacordo moral ainda permanecer na sociedade. Acerca do conceito de véu da ignorância, ver Rawls (1993).

13 Da mesma maneira, Waldron e Tushnet, ao discutirem sobre o judicial review, em momento de crítica à legitimidade de seu exercício. (WALDRON, 2010; TUSHNET, 1999)

14 É necessário, neste momento, recorrer a um esclarecimento de ordem conceitual. Strong judicial review nem sempre será o diametralmente oposto ao weak form judicial review. Há, pelo menos, dois planos de debates centrais - muito conexos entre si - em que o termo strong judicial review é aplicado com frequência: o debate sobre o conteúdo dos direitos e o debate dos diálogos institucionais. O primeiro representa a perspectiva de strong judicial review aqui adotada, correspondendo a matérias que discutem quais e até que extensão são os direitos. O segundo representa tal oposição a weak form judicial review. Este último resta caracterizado nas propostas com o fim de elidir do judiciário o poder de proferir a última palavra. Como já mencionado, são exemplos do primeiro caso de strong judicial review, Waldron (2010) e Tushnet (1999). Como exemplo do segundo caso, no plano dos diálogos institucionais, cita-se Dixon (2011). 
A contribuição de Jeremy Waldron será de especial relevância para essa compreensão filosófica de supremacia judicial. Esse autor, ao estabelecer condições em que fosse possível enfrentar a essência da oposição ao judicial review, elenca quatro pressupostos, os quais poderão ser aproveitados na tentativa de se formular uma compreensão ontognosiológica sobre a supremacia judicial, embora sejam necessários alguns ajustes.

Os critérios elencados pelo autor foram os seguintes: (1) "instituições democráticas em condições de um funcionamento razoavelmente boas, incluindo um legislativo representativo, eleito por sufrágio adulto universal"; (2) "um conjunto de instituições judiciais, também em boas condições de funcionamento, erigidas sobre uma base não representativa para conhecer de ações individuais, resolver controvérsias e defender o Estado de Direito"; (3) "um comprometimento da parte da maioria dos membros da sociedade e da maioria de suas autoridades com a ideia de direitos individuais e de minorias"; e (4) "discordância persistente, substancial e de boa-fé quanto a direitos (isto é, quanto ao que realmente significa o comprometimento com direitos e quais são suas implicações) entre os membros da sociedade que estão comprometidos com a ideia de direitos". (WALDRON, 2010, p. 106)

Em relação às situações já apresentadas, o que se propõe de alteração é o seguinte: ao invés de serem consideradas como pressupostos ao argumento essencial de oposição ao judicial review, tais situações sejam consideradas como fatores de potencial afastamento ou aproximação da proeminência da atividade judiciária perante os poderes eleitos ${ }^{15}$. Quan-

15 Para compreender melhor, como um aspecto metodológico, os mecanismos de
potencial aproximação ou potencial afastamento, é possível recorrer ao momento em
que Habermas estabelece pressupostos a sua teoria da ação comunicativa, quais sejam:
um pleno entendimento pelos membros dos significados e da linguagem, consciência
de que são racionalmente responsáveis e a consideração de que, qualquer que seja o
consenso alcançado pela justificativa racional, após passar por critérios de verdade e
de justiça, os participantes acreditarão que o resultado não é falso ou equivocado. Há
autores que criticam esta teoria dizendo que tais pressupostos representam situações
utópicas e idealísticas, consequentemente, que impossibilita o alcance de um consenso.
Porém, Habermas responde afirmando que suas condições são unicamente potenciais de
racionalidade, ou seja, à medida que são atendidos no momento da ação comunicativa,
conferem uma legitimidade maior à opinion-and will-formation, mas não se configuram 
do, por um lado, observam-se fatores de potencial afastamento, significa que há uma hipotética dificuldade de se alcançar a supremacia judicial abstrata. Quando, por outro lado, observam-se fatores de potencial aproximação, significa que há uma hipotética facilitação de seu destaque, o que configura a supremacia judicial abstrata. Essa alteração metodológica, que desdobra alguns pressupostos em fatores de potencialidade, é a primeira adaptação necessária. As demais são específicas de cada um dos pressupostos, singularmente apreciados a seguir.

\section{O Bom Funcionamento dos Poderes Eleitos}

O primeiro pressuposto ao argumento essencial ao judicial review, o bom funcionamento das instituições democráticas é, na verdade, uma situação estruturada em plano hipotético ${ }^{16}$. Waldron o teoriza visando

como pré-requisito para o alcance do consenso. Esses artifícios metodológicos de potencial aproximação e potencial afastamento devem ser compreendidos em sentido similar. Não se trata de critérios rígidos sem os quais a supremacia judicial abstrata seja inalcançável, mas fatores que, analisados conjuntamente, são capazes de ilustrar, melhor ou pior, este desenho institucional de prevalência do judiciário. Os pressupostos da ação comunicativa podem ser observados no trecho a seguir: "To illustrate Habermas's approach further, imagine that a dispute arises within a group and that its members wish to resolve it consensually on the basis of validity claims. According to Habermas, conflict resolution on the basis of reasoned agreements involves at least three idealizing assumptions: members must assume they mean the same thing by the same words and expressions; they must consider themselves as rationally accountable; and they must suppose that, when they do arrive at a mutually acceptable resolution, the supporting arguments sufficiently justify a (defeasible) confidence that any claims to truth, justice, and so forth that underlie their consensus will not subsequently prove false or mistaken. [...] That is, these idealizations imply a tension between the facto social acceptance (soziale Geltung) of a group consensus and the idealized validity (Gültigkeit) that such a consensus must claim for itself if members are to accept it as reasonable. Communicatively achieved agreements are in principle always open to challenge, and thus are at best a precarious source of social integration" (HABERMAS, 2006, p. xv-xvi). Completa-se a ideia com a passagem a seguir: "Yet, modernity, now aware of its contingencies, dependes all the more on a procedural reason, that is, on a reason that puts itself on trial". (HABERMAS, 2006, p. xli)

16 Considere-se uma questão de ordem meramente terminológica quando Waldron define instituições democráticas. A intenção era referir-se às instituições pertinentes ao 
condições de atividade que entende serem ideais. Tal fator é caracterizado, com isso, da seguinte maneira: "um sistema político amplamente democrático, com voto universal adulto e um legislativo representativo, com eleições imparciais e regulares" (WALDRON, 2010, p. 106-107). Aparentemente, funda-se em conceitos como autonomia política, livre concorrência política e periodicidade dos mandatos eletivos. Outras características são, ainda, somadas a tais condições ideais de funcionamento, como "numeroso", "acostumado a lidar com questões difíceis [...] de justiça e de política social", "bicameralismo", "partidos políticos", além de uma série de prerrogativas típicas de um complexo processo legislativo (WALDRON, 2010, p. 107). Dois valores parecem ser centrais dentro de tais condições: a ideia de responsabilidade e a de igualdade política ${ }^{17}$.

governo representativo e eleito pelo voto popular. Entende-se, aqui, que não seja, em rigor, adequado excluir o próprio judiciário desta ideia de instituições democráticas. Admitir o termo instituições democráticas, com esta restrição, parece reduzir o próprio entendimento da ideia de democracia à representação popular. Por mais que não se pretenda, neste trabalho, estabelecer um conceito próprio de democracia ou imergir em uma discussão mais profunda sobre o tema, certamente, a ideia de democracia adotada não se resume a este plano. A compreensão de uma instituição democrática talvez envolva outros critérios, sobretudo no plano da concepção política de justiça de base rawlsiana. De acordo com estes critérios de avaliação sobre o exercício da atividade institucional, é possível, inclusive, que se chegue à conclusão de um poder eleito não ser democrático e, ao mesmo tempo, o judiciário o ser. Portanto, o termo instituições democráticas adotado por Waldron, a partir de então, será substituído por outros como instituições do governo ou poderes eleitos, evitando-se uma redução da ideia de democracia à dinâmica representativa. Para um estudo mais aprofundado no sentido de avaliar quais seriam as situações capazes de caracterizar uma instituição como democrática ou não, ver Bolonha, Rangel e Almeida (2011).

${ }_{17}$ Some-se à última dessas ideias, a de igualdade política, a visão de Mark Tushnet (1999). Segundo ele, é possível que haja certa diferença entre minorias políticas. O autor, ao debater sobre sua versão de judicial review, não se afastando do conteúdo dos direitos como principal parâmetro, afirma que a defesa das minorias somente deva ocorrer quando observada a impossibilidade de sua organização com significativo potencial de representatividade. Com isso, se uma minoria é apta a se representar nas instituições de governo e não o consegue por não se organizar politicamente, não deve ser protegida pela perspectiva contramajoritária de judicial review. Assim, somente as minorias marginalizadas dos procedimentos representativos da vida política devem ser objeto de defesa do judicial review. (TUSHNET, 1999) 
Este primeiro pressuposto de Waldron pode auxiliar a compreensão abstrata da supremacia judicial de um modo muito singelo. A reunião de todas essas situações configura um quadro hipotético capaz de enfraquecer a necessidade de destaque da atividade judiciária. Dessa forma, trata-se de fator de potencial afastamento da supremacia judicial. Talvez não seja adequado afirmar que a reunião de condições ideais de funcionamento, como as referidas anteriormente, elimine a possibilidade de um desenho institucional marcado pelo destaque do judiciário de maneira abstrata, mas há uma tendência de redução da importância de sua atividade perante os poderes eleitos.

\section{O Bom Funcionamento da Atividade Judiciária}

Após definir o que compreende como bom funcionamento do governo, Waldron estabelece seu entendimento hipotético sobre o bom funcionamento da atividade judiciária. Uma aparente exigência, nesse âmbito, é a independência do Judiciário, ou seja, sua aptidão em ser o poder de Estado estanque à dinâmica político-partidária típica dos poderes eleitos. Waldron destaca que muitos autores defendem a ideia de independência judicial da seguinte forma: "[...] porque significa que os tribunais podem deliberar sobre princípios sem serem distraídos por pressões populares e permanecerem invulneráveis ao clamor público" (WALDRON, 2010, p. 108-109 ${ }^{18}$. Somam-se a essa condição ideal uma infraestrutura básica de qualidade, quando o autor menciona o termo "boa estrutura de funcionamento", e a previsão normativa para o exercício do judicial review.

O conjunto de tais situações ideais de funcionamento se apresenta como um claro fator de potencial aproximação da supremacia judicial abstrata. Enquanto o primeiro fator - o bom funcionamento dos poderes eleitos - terá potencial de afastamento da proeminência do judiciário, este remontará à tendência de seu protagonismo.

\footnotetext{
${ }^{18} \mathrm{O}$ estudo prático e historicamente contextualizado da supremacia judicial, entretanto, apresenta situações particulares que parecem guardar certa oposição a esta visão hipotética. Para um estudo mais aprofundado a esse respeito, ver Pildes e Levinson (2006) e Pildes (2011).
} 
Waldron concebe algumas situações típicas da atividade judiciária que concorrem para sua fragilidade no exercício do judicial review: (1) os tribunais "não agem por impulso próprio ou por referência abstrata, mas, antes, respondem a reivindicações particulares apresentadas por litigantes particulares; (2) os tribunais "lidam com questões no contexto de apresentação binária e contenciosa"; e (3) os tribunais "remetem às suas próprias decisões anteriores e as aperfeiçoam em aspectos que parecem relevantes ao caso em questão" (WALDRON, 2010, p. 109). Talvez, tais situações tipicamente judiciais sejam capazes de, até mesmo, aumentar o potencial de aproximação do protagonismo judicial. Concebendo-se um desenho institucional em que, hipoteticamente, o judiciário não esteja submetido a - ou até esteja, mas não respeite - essas "situações tipicamente judiciais", amplia-se o escopo da atividade judiciária. Tal abertura para a atividade pode ensejar certo destaque perante os poderes eleitos.

\section{O Comprometimento com os Direitos}

O terceiro pressuposto ao argumento essencial de Waldron - o comprometimento com os direitos - considera que, apesar de haver interesses próprios, os indivíduos se comprometem com os direitos atualmente. Como exemplo, há o reconhecimento voluntário da existência de direitos pertinentes a minorias políticas (WALDRON, 2010, p. 110-111). Waldron (2010), embora defenda a admissão de que há um desacordo moral na sociedade sobre o conteúdo dos direitos, acredita em um consenso moral acerca da necessidade de seu respeito. Em formulação crítica ao pensamento de Ronald Dworkin, afirma que os direitos são levados a sério, no momento em que estão imersos no desacordo moral, justamente por este fato: se há comprometimento com o respeito aos direitos, os indivíduos irão desenvolver o debate sobre o seu conteúdo, levando a um desacordo moral com base em suas visões particulares" ${ }^{19}$. Segundo o autor "o comprometimento com direitos não são palavras vazias”, pois os membros da sociedade "[...] se importam com eles, examinam e debatem ativamente

\footnotetext{
${ }^{19}$ Sobre Ronald Dworkin, no que tange à obra objeto de tais críticas, entre outras, ver Dworkin (1977).
} 
os seus próprios pontos de vista e o de outros e estão alerta para questões de direitos com relação a todas as decisões sociais que são investigadas ou discutidas em seu meio." (WALDRON, 2010, p. 111) ${ }^{20}$

Esse pressuposto de Waldron, em particular, exige maiores adaptações para que possa auxiliar a compreensão ontognosiológica de supremacia judicial. Por um lado, se, hipoteticamente, os direitos são efetivamente levados a sério com um rigoroso comprometimento, dificilmente haverá lacunas na atividade dos poderes eleitos, o que reduz, teoricamente, o espectro de atuação em que pode se lançar o judiciário; por outro lado, se há pouco comprometimento, nada impede que o próprio judiciário talvez se comporte com passividade em relação a sua efetivação. A dificuldade em lidar com esse fator é ter de considerar um grau mediano de comprometimento, em que seja possível cogitar que os poderes eleitos não promovam os direitos e sem que o judiciário mantenha-se em um quadro inerte. Nesse tipo de situação especialmente, o comprometimento com os direitos seria um potencial de aproximação da essência da supremacia judicial. Se, ao contrário, houvesse um comprometimento mais intenso ou muito reduzido, tornar-se-ia difícil cogitar a necessidade de desenvolvimento do judiciário nesse sentido. Para situações hipotéticas de significativo comprometimento por parte dos poderes eleitos, bem como para as situações de acentuado descompromisso por parte do judiciário, parece tratar-se de um potencial de afastamento da supremacia judicial em sua concepção abstrata ${ }^{21}$.

${ }^{20}$ Segundo Waldron, essa ideia é reforçada pelo fato de se buscarem Declarações de Direitos oficiais e escritas. Com isso, estende sua crítica ao defender a desnecessidade de tais declarações e de sua respectiva tutela por parte do judiciário para que o compromisso com os direitos seja garantido. Discorda que o judicial review "[...] seja uma maneira de institucionalizar ou administrar o comprometimento de uma sociedade com direitos" (WALDRON, 2010, p. 112-113). Waldron parece indicar, ainda, que as Declarações de Direitos não possuem a ínsita pretensão de estabelecer o conteúdo dos direitos, como se pode observar no trecho a seguir: "[...] a retórica insípida da Declaração de Direitos foi projetada simplesmente para lidar de maneira habilidosa com as discordâncias reais e razoáveis que são inevitáveis entre pessoas que levam direitos a sério, durante tempo suficiente para ver uma Declaração promulgada". (WALDRON, 2010, p. 116)

${ }^{21}$ Neste momento, talvez seja interessante refletir qual seria o grau de comprometimento com os direitos no Brasil particularmente. Não é objetivo deste trabalho fornecer meios para avaliar esse grau de comprometimento, mas, mesmo de uma forma mais 


\section{O Desacordo Moral sobre o Conteúdo dos Direitos}

O último pressuposto trazido por Waldron em suporte de seu argumento central de oposição seria admitir que "[...] há dissenso substancial em relação a quais direitos existem e em relação àquilo a que equivalem" (WALDRON, 2010, p. 113) 22. Com isso, a partir do momento em que nos comprometemos com os direitos e assumimos o ônus de respeitá-los, é natural que essa própria preocupação dê ensejo a um desacordo moral acerca de seu conteúdo. Dizer que o conteúdo dos direitos é objeto desse substancial desacordo significa dizer que nos preocupamos tanto em lhes garantir e conferir sua efetivação que a difícil tarefa de definir, primeiramente, quais são esses direitos dignos de comprometimento e, segundamente, até que limites eles se estendem são duas questões de fundamental importância na ordem constitucional democrática. É possível, portanto, associar perfeitamente as ideias de comprometimento e desacordo. Com o comprometimento, há a ideia de zelo e respeito pelos direitos; com a ideia de desacordo moral, apesar de devidamente aceitos e respeitados, tais direitos não possuem uma forma bem definida em seus significado e amplitude. Waldron entende o desacordo como nada além de um fator que dificulta o desenvolvimento da atividade legislativa, e não uma disfunção neste poder. Segundo o autor, é de fundamental relevância a existência de procedimentos responsáveis e deliberativos que discutam o conteúdo dos

abrangente, não aparenta nenhum absurdo cogitar que contemporaneamente se encontre em um grau mediano. Há estudos, por exemplo, que caracterizam a falta de atividade do Legislativo a partir de um silêncio eloquente, segundo o qual este poder estaria mantendo um comportamento de pouca atividade de forma deliberada, ciente, em muitos casos, de que este vácuo será preenchido por outras instituições, a exemplo do Judiciário. Tradicionalmente, a teoria do direito trata silêncio eloquente e lacuna como espécies de inatividade legislativa que não se confundem, podendo-se, no plano constitucional, recorrer à jurisprudência alemã no que tange ao beredtes schweigen (LARENZ, 1997).

22 Para uma compreensão mais aprofundada sobre o conceito de incompletely theorized agreements, é possível recorrer ao livro-base da teoria minimalista ou a um artigo desenvolvendo a ideia, ambos de autoria de Sunstein, publicados respectivamente em 1999 e 2007. Para compreender melhor o conceito rawlsiano de overlapping consensus, é possível recorrer a Rawls (1993), obra que representa uma grande revisão de sua teoria da justiça, transformando sua perspectiva metafísica em uma compreensão eminentemente política. 
direitos em questões controvertidas no interior dos poderes eleitos, aqueles que estariam, de acordo com razões estruturais, mais bem preparados para tal encargo.

Quando se busca adaptar o pressuposto mencionado para que sirva como um fator de potencial afastamento ou aproximação da proeminência da atividade judiciária, é necessário ressaltar que há uma particular dificuldade. Isso porque o afastamento ou a aproximação dependerá do próprio comportamento do judiciário ao enfrentar controvérsias envolvidas em um forte desacordo moral no plano social. Com efeito, o enfrentamento da controvérsia pelo judiciário não necessariamente resultará em um consenso moral na sociedade ${ }^{23}$, e, dependendo da maneira como se enfrenta tal controvérsia, os resultados podem fazer deste fator de potencial algo positivo ou negativo para o protagonismo da atividade judiciária. Em outras palavras, um intenso enfrentamento pela via judicial do desacordo moral pode ensejar tensões entre o judiciário e os poderes eleitos e, até mesmo, entre aquele e a sociedade. Consequentemente, dessa tensão podem surgir resistências sobre a autoridade da decisão judicial no plano do reconhecimento, em detrimento do desenho institucional da supremacia judicial em sua concepção abstrata.

Quando aprofundada a questão do desacordo moral sobre o conteúdo dos direitos, Waldron elenca três planos distintos para seu desenvolvimento: (I) filosófico; (II) de princípios abstratos; e (III) de ações estritamente individuais. Neste momento, em especial, é possível considerar a importância do conceito de incompletely theorized agreements, desenvolvido no âmbito da teoria minimalista de Cass Sunstein, e fortemente influenciado pelo conceito rawlsiano de overlapping consensus. Ambos buscam uma forma de superar a dificuldade do dissenso por meio de um enfoque prático da atividade decisional. De acordo com esses conceitos,

23 A decisão do judiciário, ao enfrentar a controvérsia não superará, de imediato, o desacordo moral no plano social, mas, ao contrário do que entende Waldron, nem mesmo a promulgação de uma lei sobre o mesmo assunto teria a prerrogativa de encerrar esse dissenso necessariamente. Tanto o primeiro quanto o segundo caso exigem uma análise em nível de autoridade, dentro do debate acerca da rule of recognition. Este, porém, não é objeto do presente artigo. É possível recorrer a um trabalho anterior de Waldron (1993) em que essa temática é analisada. Acerca da rule of recognition, ver Hart (1961). 
quanto mais as controvérsias são levadas ao plano filosófico, ou seja, quanto mais se analisa a questão deeply - afastando-se do modelo minimalista judicial -, mais difícil se torna a obtenção de uma decisão consensual $^{24}$. Em contrapartida, a apresentação de argumentos firmados em situações práticas de solução, sem uma fundamentação filosoficamente aprofundada - ou seja, shallowly -, supera, em grande parte, o desacordo moral. Com base nesta estria de raciocínio, deve-se buscar discutir a controvérsia sempre a partir de um plano mais prático, ou seja, menos aprofundado filosoficamente ${ }^{25}$.

Voltando-se à dificuldade do enfrentamento judicial de controvérsias de grande dissenso, pode-se afirmar que, quanto mais profundo é o plano da decisão, mais chances existem de estabelecimento de tensões entre o judiciário e os poderes eleitos ou a população. Em certas situações, pode ocorrer o desacordo moral sobre o conteúdo de um direito específico ainda não alcançar maturidade e estar longe de ser superado. O enfrentamento dessa questão pelo judiciário de maneira aprofundada geralmente ocorre pela adoção de uma das versões morais daquele desacordo ${ }^{26}$. Tal comportamento por parte do judiciário pode ser um tanto precipitado, já que pode ensejar efeitos graves sobre sua própria atividade. Um efeito de desprestígio, por exemplo, fatalmente concorreria para seu enfraquecimento.

Por tais razões, acredita-se que, a depender da forma que se exerce a atividade judiciária, o enfrentamento judicial de um substancial desacordo moral sobre determinada controvérsia pode representar um fator de potencial afastamento ou aproximação de seu destaque perante os poderes eleitos. Não constitui, de fato, objeto deste artigo a apresentação

\footnotetext{
24 O termo deeply, aplicado anteriormente, bem como o termo shallowly, utilizado logo em seguida, representam uma referência direta à metodologia de estudo minimalista encontrada em Sunstein (1999).

25 A teoria do minimalismo judicial também sustenta outra variável ao lado desta análise deep ou shallow, relativa à profundidade das discussões: a variável de análise narrow ou wide, versando sobre a amplitude atribuída às discussões acerca do tema. (SUNSTEIN, 1999)

26 O termo "versões morais" pode ser perfeitamente substituído por doutrinas morais. (RAWLS, 1993)
} 
prescritiva de um modelo judiciário para o alcance de uma condição privilegiada no plano constitucional democrático, particularmente ao enfrentar questões de profundo desacordo. Essa tarefa, em primeiro lugar, exigiria uma mínima justificação de critérios capazes de identificar o grau do desacordo existente e, em segundo lugar, identificar a partir de que ponto as decisões estariam incorrendo em uma fundamentação filosófica mais aprofundada. $\mathrm{O}$ que se pretende estabelecer aqui é meramente que, no plano hipotético, quanto mais essa discussão profunda sobre o conteúdo dos direitos ocorrer, mais haverá potencialidade de afastamento da preponderância do judiciário. Por mais que isso pareça paradoxal, uma vez que supremacia judicial pareça ser uma incondicional submissão dos demais poderes e dos jurisdicionados, é preciso considerar o plano das repercussões advindas dessa forma de exercício da atividade judiciária. A supremacia judicial abstrata pode ser um estado de preponderância da atividade judiciária, mas, em nenhum momento, afirma-se a irreversibilidade desse quadro. Por isso a importância de se considerarem os efeitos de uma atuação tendente a se chocar com a população.

\section{Conclusões}

Após analisar como cada uma de tais situações é capaz de promover um maior ou menor destaque, no plano hipotético-filosófico, da atividade judiciária, conclui-se que é possível investigar o que seria a essência da supremacia judicial - ou, em outras palavras, a supremacia judicial em sua concepção abstrata. Em primeiro lugar, uma boa estrutura de funcionamento nos poderes eleitos será um fator de potencial afastamento da preponderância do judiciário. Em segundo lugar, uma boa estrutura de funcionamento do judiciário permitirá uma aproximação dessa proeminência. Em terceiro lugar, o comprometimento com os direitos poderá oferecer situações distintas: um mínimo comprometimento talvez não mova o judiciário; um grande comprometimento afasta a necessidade de uma atuação avant garde, mas um comprometimento médio, na particular hipótese de o legislativo ser menos comprometido do que o judiciário, talvez represente o maior potencial de aproximação desse desenho. Em quarto e último lugar, a existência de um desacordo moral sobre o conte- 
údo dos direitos dependerá da maneira como o judiciário atua perante as controvérsias mais sensíveis: o teor filosoficamente aprofundado da fundamentação da decisão judicial parece ser "diretamente proporcional" ao grau de tensão entre o judiciário e os poderes eleitos ou entre aquele e a própria sociedade. Tal tensão pode gerar prejuízos à autoridade da decisão judicial, concorrendo para uma reversão do eventual quadro de preponderância do judiciário. Portanto, o enfrentamento judicial de questões envolvidas em forte desacordo moral na sociedade, a depender da forma de seu exercício, pode gerar efeitos diretos sobre seu desenho institucional, afastando a concepção abstrata de supremacia judicial. Em síntese, menor será a aproximação da essência da supremacia judicial não pelo exercício em si, mas pelos efeitos que podem advir da tensão dele resultante.

\section{Referências}

BOLONHA, Carlos; RANGEL, Henrique; ALMEIDA, Maíra. A teoria de John Rawls e as instituições democráticas. Revista JurisPoiesis, Rio de Janeiro, ano 14, n. 14, p. 89-102, jan.-dez. 2011.

BRANDÃO, Rodrigo. Supremacia judicial versus diálogos

institucionais: a quem cabe a última palavra sobre o sentido da Constituição? Rio de Janeiro: Lumen Juris, 2012.

DIXON, Rosalind. The Supreme Court of Canada: charter dialogue and deference. Chicago Public Law \& Legal Theory Working Papers Series, Chicago, n. 284, 2009.

. Weak form judicial review and the american exceptionalism.

Chicago Public Law and Legal Theory Working Paper Series, Chicago, n. 348, 2011.

DWORKIN, Ronald. Taking rights seriously. Cambridge: Harvard University Press, 1977.

ELY, John. Democracy and distrust: a theory of judicial review. Cambridge: Harvard University Press, 1980.

GRIFFIN, Stephen. American constitutionalism: from the theory to politics. Princeton: Princeton University Press, 1996. 
. The age of Marbury: judicial review in a democracy of rights. In: TUSHNET, Mark (Ed.). Arguing Marbury v. Madison. Sanford: Sanford University Press, 2005.

HABERMAS, Jürgen. Between facts and norms: contributions to a discourse theory of law and democracy. Cambridge: The MIT Press, 2006.

HART, Herbert. The concept of law. Oxford: Oxford University Press, 1961.

HOGG, Peter; BUSHELL, Allison. The Charter dialogue between courts and legislatures: or perhaps the charter of rights isn't such a bad thing after all. Osgoode Law Review, Toronto, v. 35, n. 1, 1997.

LARENZ, Karl. Metodologia da ciência do direito. Lisboa: Fundação Calouste Gulbenkian, 1997.

NELSON, Willam. Marbury v. Madison: the origins and the legacy of judicial review. Lawrence: University Press of Kansas, 2000.

PILDES, Richard; LEVINSON, Daryl. Separation of parties, not powers. Harvard Law Review, Cambridge, v. 119, n. 1, 2006.

PILDES, Richard. Why the Center Does Not Hold: the causes of hyperpolarized democracy in America. California Law Review, Berkeley, v. 99, n. 2, 2011.

RAWLS, John. Political Liberalism. New York: Columbia University Press, 1993.

SUNSTEIN, Cass. Incompletely theorized agreements in constitutional law. Chicago Public Law and Legal Theory Working Paper Series, Chicago, n. 147, 2007.

. One case at a time: judicial minimalism in the Supreme Court. Cambridge: Harvard University Press, 1999.

THAYER, James. The origin and scope of the American doctrine of Constitutional Law. Harvard Law Review, Cambridge, v. 7, n. 3, 1893. TUSHNET, Mark. Popular constitutionalism as political law. ChicagoKent Law Review, Chicago, v. 81, n. 991, 2006. 
. Taking the Constitution away from the courts. Princeton: Princeton University Press, 1999.

VERMEULE, Adrian. Mechanisms of democracy: institutional design writ small. Cambridge: Oxford University Press, 2007.

WALDRON, Jeremy. A right-based critique of constitutional rights. Oxford Journal of Legal Studies, Oxford, v. 13, n. 1, 1993.

. A essência da oposição ao judicial review. In: BIGONHA, Antonio; MOREIRA, Luiz. Legitimidade da jurisdição constitucional. Rio de Janeiro: Lumen Juris, 2010.

WHITTINGTON, Keith. Political foundations of judicial supremacy: the Presidency, the Supreme Court, and Constitutional Leadership in U.S. History. Princeton: Princeton University Press, 2007.

Carlos Bolonha é Doutor e Mestre em Teoria do Estado e Direito Constitucional pela Pontifícia Universidade Católica do Rio de Janeiro (PUC-RJ). Professor Adjunto do Departamento de Direito do Estado e do Programa de Pós-Graduação em Direito da Universidade Federal do Rio de Janeiro (UFRJ). E-mail: bolonhacarlos@gmail.com.

Endereço profissional: Universidade Federal do Rio de Janeiro. Faculdade de Direito. Rua Moncorvo Filho, 08. CEP: 20211-340. Centro, Rio de Janeiro/RJ.

Fabrício Faroni é Mestrando em Teorias Jurídicas Contemporâneas pelo Programa de Pós-Graduação em Direito da Universidade Federal do Rio de Janeiro. Procurador Federal.E-mail: faroni@uol.com.br.

Endereço profissional: Universidade Federal do Rio de Janeiro. Faculdade de Direito. Rua Moncorvo Filho, 08. CEP: 20211-340. Centro, Rio de Janeiro/RJ.

Henrique Rangel é Graduando em Direito pela Faculdade Nacional de Direito da Universidade Federal do Rio de Janeiro.E-mail: henriquerangelc@gmail.com. Endereço profissional: Universidade Federal do Rio de Janeiro. Faculdade de Direito. Rua Moncorvo Filho, 08. CEP: 20211-340. Centro, Rio de Janeiro/RJ. 